\title{
CUSTEAMENTO ABC NUMA ORGANIZAÇÃO HOSPITALAR: UM ESTUDO COMPARATIVO DO CUSTO DE CIRURGIAS ELETIVAS COM VALORES REMUNERADOS POR PLANOS DE SAÚDE
}

\author{
ABC Costing Organization in Hospital: A Comparative Study of the Cost of Elective \\ Surgery with Reimbursements Paid by Health Plans
}

Domingos Fernandes Campos

Universidade Potiguar - RN domingos_campos@uol.com.br

\section{Isabel Cristina Pansiera Marques Universidade Potiguar - RN marques_enf@yahoo.com.br}

Submissão: 14/06/2012

Aprovação: 02/10/2013

\section{RESUMO}

Este artigo tem como objetivo calcular os custos com base nas atividades do centro cirúrgico de um hospital privado e fazer uma análise comparativa com a remuneração oferecida por diferentes planos de saúde. Uma abordagem sistêmica foi utilizada como suporte ao desenvolvimento do custeamento, especialmente, na descrição das atividades e inter-relações dos subsistemas que conformam o complexo hospitalar. Através da revisão de metodologias brasileiras e internacionais, foi estabelecido um quadro referencial para o desenvolvimento do trabalho. A abordagem sistêmica e o custeamento com base na atividade foram aplicados em todos os centros de custos do hospital em estudo. Os reembolsos pagos pelo sistema público de saúde ficaram abaixo dos valores custeados e houve variações significativas entre os reembolsos dos planos privados. Os resultados sugerem que os planos de saúde trabalham com metodologias não convergentes na formação de suas tabelas de remuneração.

Palavras-chave: Custos. Custeamento ABC. Hospital. Abordagem Sistêmica. 


\begin{abstract}
This article aims to calculate the costs based on the activities of the operating room of a private hospital and make a comparative analysis with the compensation offered by different health plans. A systemic approach was used to support the development of costing, especially the description of the activities and interrelationships of the subsystems that make up the hospital complex. Through a review of Brazilian and international methodologies, a frame of reference was established for the development work. The systemic approach and costing based on activity were applied to all cost centers of the hospital. The reimbursements paid by the public health were insufficient to cover the costs and values were significant differences between the repayments of private plans. The results suggest that health plans work with nonconvergent methodologies in shaping their rates of remuneration.
\end{abstract}

Keywords: Costs. Costing ABC. Hospital. Systemic Approach. 


\section{INTRODUÇÃO}

Assistência com acesso limitado, altos custos e qualidade insatisfatória são aspectos relevantes que marcam a atual situação do sistema de saúde. As instituições hospitalares são organizações complexas que atuam na área de serviços de hospedagem, educação, prevenção, pesquisa, tratamento e diagnóstico. O desempenho do sistema hospitalar depende, fundamentalmente, da maneira como os diferentes setores se ajustam, trabalham e se completam. Para que um hospital possa atingir excelência na prestação de seus serviços, é essencial que realize constantes investimentos, melhore sua estrutura física, adéqüe tecnologicamente os materiais e equipamentos e invista na qualificação de seus colaboradores. As fontes de obtenção de receitas necessárias à atualização de seus recursos organizacionais estão atreladas às tabelas de remuneração de procedimentos médicos das operadoras que administram os planos de saúde. Abbas (2001) aponta que boa parte das instituições hospitalares do país não possui uma gestão adequada de seus custos dificultando a obtenção de receitas, compatíveis com as necessidades de manutenção destas organizações.

Dentre os métodos para realizar a mensuração de custos estão os por Absorção, Direto e o Baseado em Atividades - ABC. Todos, de maneira geral, apresentam limitações na sua função de mensurar custos. Essas limitações são oriundas, principalmente, pela dificuldade de alocar custos indiretos de forma objetiva a produtos e serviços produzidos ou realizados durante o período de sua ocorrência. $\mathrm{O}$ diferencial do Método $\mathrm{ABC}$ é o foco na atividade e como esta consome os recursos (MARTINS, 2003). A utilização do Método ABC pode auxiliar a gestão dos custos nos hospitais. Aplicado na mensuração dos procedimentos médicos, permite sua quantificação, criando unidades de medidas homogêneas, com terminologias usualmente utilizadas por profissionais ligados à área médica e proporciona uma melhor compreensão dos custos por parte dos mesmos.

Embora tenha uma concepção aparentemente simples, o custeamento com base na atividade requer uma compreensão mais profunda dos processos e atividades realizados no âmbito organizacional, incluindo todos os fluxos de materiais e informações necessários ao seu bom funcionamento. Ademais, pressupõe o estabelecimento de uma estrutura de registro e controle de custos e despesas vinculadas aos diversos centros de custo, bem como de uma base informacional que alimente o sistema operacional com variáveis e medidas de desempenho apropriadas ao seu acompanhamento. O objetivo deste trabalho é desenvolver um custeamento com base na atividade de uma organização hospitalar privada, utilizando uma 
abordagem sistêmica (AS) na descrição dos subsistemas e atividades para mapear as interrelações específicas que conformam o complexo hospitalar. Ao final, calcular os custos de um grupo de cirurgias eletivas e compará-los à remuneração oferecida pelos planos de saúde. 


\section{CUSTOS EM INSTITUIÇÕES DE SAÚDE}

No Brasil, a universalização do acesso à saúde e o aumento da expectativa de vida da população têm contribuído significativamente para o aumento dos custos hospitalares, com reflexo direto na qualidade do serviço e nos recursos públicos disponíveis para seu financiamento. Uma respectiva análise é necessária para que se possa concluir e avaliar o desempenho como subsídio para novas decisões (SANTOS, 2006).

A busca por mecanismos de controles que forneçam subsídios para uma adequada análise de processos e, por conseqüência, tomadas de decisões pautadas numa gama maior de informações tem sido meta de diferentes instituições. Com foco nestes objetivos, estudiosos buscam aplicar métodos de custeamento que sejam adequados para a realidade das organizações e que tragam uma maior compreensão de como os recursos são consumidos, bem como estes podem ser controlados ampliando, desta forma, a eficiência dos processos desenvolvidos em organizações hospitalares. Lungen e Lapsley (2003) relatam a experiência alemã, na qual os hospitais passaram a ser reembolsados pelo governo de acordo com os grupos de diagnósticos médicos relacionados. Para os autores, a reforma no sistema de saúde é vista como uma tentativa do governo de agir sobre os princípios de base científica e não significa que resultará na redução dos gastos globais. A diminuição mais significativa nos custos, com a introdução do pagamento por diagnóstico prospectivo de grupos relacionados (Diagnosis Related Groups - DRGs), se deve ao reembolso das despesas em uma base por tipo de caso. A introdução dos DRGs pode ser vista como um ato de política baseada em evidências, no entanto, resta saber se o pagamento por diagnóstico pode diminuir as despesas hospitalares (LUNGEN; LAPSLEY, 2003). Os autores acreditam que é possível que os DRGs apenas redistribuam os recursos financeiros e aumente a eficiência dos hospitais, mas não diminua a soma de todos os custos.

Negrini et al. (2004) analisam as metodologias de custeio utilizadas por diferentes instituições européias para tentar descrever os componentes básicos de um método padronizado, que pudesse ser aplicado em toda a Europa. O objetivo é a troca de informações entre diferentes instituições, comparando resultados com os valores obtidos no custo por dia de internação. A diversidade de métodos de custeio utilizados conduziu a uma fraca validação e a impossibilidade de se comparar os resultados entre essas instituições. Os métodos discutidos na pesquisa tornam evidente a inexistência de metodologias padronizadas para a determinação dos custos precisos. Em uma instituição de saúde a forma como são 
apresentadas as informações de custos, sob a orientação do custeio baseado em atividades, proporciona maior abrangência da função de gestão de custos. Um aspecto importante que chama atenção nas entidades hospitalares é o processo de mudança por que passam estas instituições em relação à remuneração pelos serviços prestados (St. HILAIRE; CRÉPEAU, 2000).

Jacobs et al. (2002) relatam a experiência obtida no Canadá onde uma lista de "custos" foi introduzida. Esta lista prevê serviços associados aos custos e permite a comparação entre os estudos de diferentes instituições. A medida é local, mas uma abordagem semelhante poderia ser utilizada como ponto de partida para o desenvolvimento de uma metodologia de custos que fosse comum a diversos países (NEGRINI et al., 2004).

Ching (2010) complementa que os maiores benefícios esperados com o custeamento são um melhor entendimento das operações da organização, uma contribuição para melhoria dos processos e um custeio mais exato dos serviços prestados aos pacientes.

No que se refere aos os sistemas de pagamentos, as informações sobre custos reais, o volume de serviço e as características dos prestadores e compradores de serviços de saúde afetam a fixação de preços. Através da revisão de metodologias e comparando práticas norteamericanas e de outros países, os autores apontam a limitada disponibilidade de informações sobre custos, incidência e características do paciente como o principal entrave no desenvolvimento de sistemas de remuneração. Consideram que os maiores benefícios propiciados pelo método $\mathrm{ABC}$ residem na monitoração da eficiência e na possibilidade de feed back para um melhor gerenciamento dos processos (WATERS; HUSSEY, 2004).

A alocação de custos deve ser a questão principal dentro do sistema de contabilidade de uma empresa. A questão central é saber quanto e quão indireto é um custo em relação a um determinado serviço (STRUETT, 2007). No Japão, Toyabea et al. (2005) apresentam um método para calcular os custos de materiais descartáveis utilizados durante as cirurgias. Consideram que o consumo dos descartáveis está relacionado com o tempo de duração do procedimento médico e que variam significativamente conforme o tipo de cirurgia. Apontam para a necessidade de conhecimento dos custos exatos por cirurgia para que ocorra a redução na variância entre as diferentes equipes médicas.

Em estudo realizado na Dinamarca, Larsen e Skjoldborg (2004) comparam os sistemas de custeio por absorção com o ABC e os DRGs para o reembolso da terapêutica de pacientes com diagnóstico de angina pectoris estável com o intuito de estudar a influência dos dias de internação no custo do tratamento. $\mathrm{O}$ argumento encontrado contra a utilização dos DRGs é 
que estes podem gerar incentivos econômicos indesejáveis na classificação dos tratamentos; isso poderia ser evitado com o ABC, dado o nível de transparência na alocação dos custos. Os DRGs são calculados a partir de uma média para um determinado número de hospitais categorizando os grupos de diagnósticos. No custeamento ABC, os encargos são apurados sob medida para a organização e o processo de tratamento.

Diez e Lennertz (2009) investigaram as interdependências entre o desempenho e a facilidade de gestão de custos nos processos primários de hospitais. A partir do sistema de remuneração por DRGs e da importância dos custos, surgiu a necessidade de uma utilização otimizada de espaços físicos e a exploração dos recursos especiais nos hospitais. O modelo de custeio é baseado na gestão das instalações físicas. A pesquisa foi aplicada nos centros cirúrgicos de quatro hospitais alemães. Posteriormente, os resultados foram comparados com o sistema de pagamento por DRGs (DIEZ; LENNERTZ, 2009).

Demeerec et al. (2009) desenvolveram um estudo na Bélgica em cinco ambulatórios de especialidades médicas. Apontaram os benefícios de uma nova abordagem para a aplicação do $\mathrm{ABC}$ tendo como base trabalhos desenvolvidos por Kaplan e Anderson (2007), os quais observaram que o tempo e o custo para estimar e manter um modelo $\mathrm{ABC}$ por meio de entrevistas e re-pesquisas tem sido um grande obstáculo à adopção generalizada do $\mathrm{ABC}$. Para superar estas dificuldades, Kaplan e Anderson (2007) desenvolveram um modelo chamado time-driven activity-based costing (TDABC) ou ABC por tempo orientado. Este modelo utiliza dois parâmetros: (i) o custo unitário da capacidade de fornecimento e (ii) o tempo necessário para realizar uma operação ou de uma actividade. $\mathrm{O}$ desenvolvimento do TDABC reside no uso de equações para estimar o tempo gasto em cada atividade. Em sitemas complexos, como as instituições hospitalares, onde o tempo necessário para realizar uma atividade depende de muitos direcionadores, Demeerec et al. (2009) mostram como o TDABC pode incluir vários drivers simplificando o cálculo das equações de tempo dos processos e oferece um custo mais preciso do que o obtido com o $\mathrm{ABC}$ tradicional.

O ABC foi utilizado por Shander et al. (2010) para determinar os custos de transfusões sanguíneas em pacientes cirúrgicos de dois hospitais americanos e outros dois europeus, Áustria e Suíça. Devido à complexidade do processo foi desenvolvido um software para facilitar a aplicação do ABC. Os resultados confirmam que os custos imputáveis por unidade de sangue têm sido subestimados. Nas quatro instituições, os valores ultrapassam os relatados em estudos anteriores. Os autores observam que os custos indiretos contribuíram de $32 \%$ a 
$41 \%$ do total das despesas. Em todos os casos, estas despesas foram maiores que a aquisição de produtos sanguíneos específicos.

Os custos diretos são facilmente alocáveis aos objetos de custos, não precisando passar pelas atividades. Porém, existem outros custos, chamados indiretos, em que a alocação direta não e possível; dessa forma, são alocados às atividades, para uma posterior alocação aos objetos de custos. Nessas alocações, o Custeio Baseado em Atividades utiliza os direcionadores de custos (cost drivers) e procura retratar o que provoca os custos no processo de elaboração dos produtos (SOUZA; RAIMUNDINI; KUWABARA, 2008).

Na década de 80, estudos foram desenvolvidos no Brasil abordando a contabilidade de custos hospitalares. Um sistema de custo hospitalar deve proporcionar informações que permita aos gestores condições de melhoria nas funções de planejamento e controle das operações (MATOS, 2002). Martins (2002) afirma que a organização hospitalar alcançará seus objetivos se souber determinar o que o paciente necessita e oferecer serviços médicos que satisfaçam a essas necessidades. Vargas (2002) aplica o ABC em uma Unidade de Terapia Intensiva (UTI) dirigida a três procedimentos específicos: colecistectomia, revascularização do miocárdio e endardectomia. $\mathrm{O}$ autor conclui que em razão das diferentes quantidades de recursos dirigidos às atividades, os custos do paciente-dia da UTI podem ter valores diferentes entre si, bem como em relação aos obtidos com o custeio tradicional.

Raimundini et al. (2005) apresentam uma pesquisa bibliográfica com o objetivo de analisar os resultados apurados na aplicação do custeio baseado em atividades em hospitais e congêneres. Os autores observaram que os hospitais que utilizavam o sistema de custeio tradicional mostraram deficiência na geração de informações, salientando a variação no custo dos procedimentos, pelo motivo de o critério utilizado para alocar os custos indiretos ser subjetivo e arbitrário. O estudo demonstra que a aplicabilidade do sistema $\mathrm{ABC}$ gera informações mais precisas e confiáveis para gestão e tomada de decisão.

Em organizações hospitalares, o $\mathrm{ABC}$ pode trazer as seguintes vantagens: fornecimento de informações de custos mais exatas que representem a realidade; demonstração de vantagens em se produzir todos os serviços no próprio hospital ou optar pela terceirização e estudo de tendências e comparação de custos por diagnóstico, por atendimento médico ou por pacientes de diferentes planos de saúde.

Jericó (2008), em um Centro de Material e Esterilização (CME) de um hospital de ensino em São Paulo, utilizou o $\mathrm{ABC}$ em conjunto com a aplicação da Gestão Baseada em Atividade (Activity Based Management - ABM) possibilitando classificar as atividades 
segundo análise de valor. $\mathrm{O}$ custeio $\mathrm{ABC}$ permitiu a compreensão do processo gerador de custos e as informações ofereceram base para a mensuração de desempenho e melhorias dos processos do CME. Embora se observe evolução nas formas de custeio das instituições de saúde, Oliveira (2005) afirma que os custos dos hospitais brasileiros são muito mal elaborados e a grande maioria vive de aumentar sua tabela de preços, independentemente da análise real do seu custo hospitalar. Aplicando-se o método ABC em uma organização de saúde será possível entender melhor os custos associados com a avaliação do paciente ou com o fornecimento de testes diagnósticos, bem como os fatores que influenciam o custo.

Falk (2001) aponta que o controle de custos hospitalares tem recebido pouco espaço na literatura. As complexas unidades hospitalares sofrem com a busca de um sistema de custos que seja ideal para cada tipo de hospital, conforme sua vocação específica. O autor sugere quatro etapas, ou estágios, para a elaboração de custos na área de saúde. A Figura 1 ilustra a implantação da metodologia $\mathrm{ABC}$ para elaboração de custos na área de saúde.

Figura 1: Etapas para elaboração de custos na área de saúde.

Fonte: Adaptado de Falk, 2001.

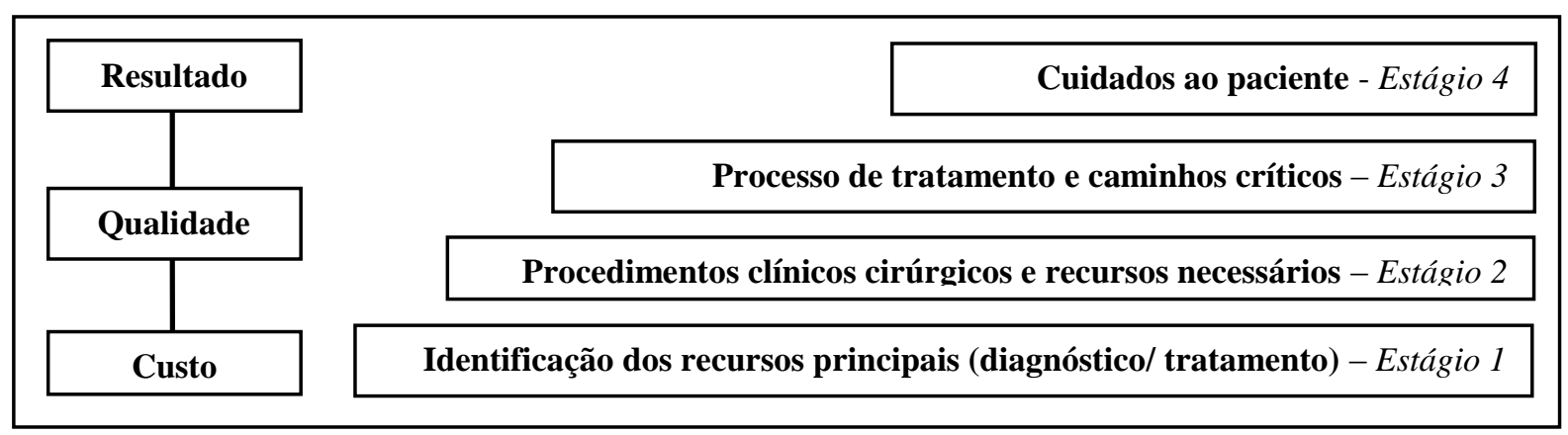

O Método ABC utiliza ferramentas, como objetos de custos, direcionadores e atividades para auxiliar seu desenvolvimento. No que se refere aos objetos de custos, Zimmerman (1997) já referia que as organizações deveriam distribuir e alocar os custos a um objeto de custo. O custo do objeto de custo é o que os gerentes normalmente desejam saber para tomar as decisões e/ou controlar o comportamento dos processos dentro da organização. Para o autor a identificação das principais atividades e a alocação de custos deve ser a questão principal dentro do sistema de contabilidade de uma empresa.

Os direcionadores de custos constituem a base para atribuir os custos das atividades aos produtos. Autores como Turney (1991), Kaplan e Cooper (1998), Boisvert (1999), Martins (2003) identificam duas categorias de direcionadores: os de recursos e os de atividades. Os direcionadores de recursos são aqueles que identificam o consumo de recursos 
pelas atividades e os direcionadores de atividades são aqueles associados ao consumo de atividades pelos objetos de custos. Martins (2003) refere que o direcionador de recurso identifica como as atividades consomem recursos e explica a relação entre recursos gastos e as atividades. Para eleger os direcionadores que melhor identificam o consumo dos recursos pelas atividades e o consumo destas pelos objetos de custos, devem ser consideradas variáveis como: a facilidade na obtenção e no processamento, a correlação entre os direcionadores e os recursos consumidos e a influência que eles terão sobre as pessoas e seu comportamento (CHING, 2010). Nakagawa (2008) considera que o direcionador de custo é um fator causal que influencia o nível e o desempenho de atividades e o consumo resultante de recursos.

Destaca-se a necessidade de que os custos devam ser alocados em cada departamento específico. Cada uma é um recurso principal para a execução das atividades que cuidam da saúde. Na realidade, cada uma das contas pode ser subdividida para melhor acompanhamento dos custos envolvidos em cada atividade.

A tomada de decisões na gestão de um complexo hospitalar necessita de informações precisas dos processos, das relações entre as unidades e destas com o meio ambiente o que torna relevante a implantação de técnicas de custeamento que reflitam as realidades. A Tabela 1 apresenta uma síntese de estudos realizados em hospitais e congêneres. 
Tabela 1: Síntese de estudos de custos realizados em hospitais.

Fonte: Elaboração própria.

\begin{tabular}{|c|c|}
\hline Autor e Ano & Enfoque \\
\hline Jacobs et al (2002) & $\begin{array}{l}\text { Lista de serviços associados aos custos para comparabilidade entre os estudos } \\
\text { de diferentes instituições hospitalares no Canadá }\end{array}$ \\
\hline Vargas (2002) & Método ABC em uma Unidade de Terapia Intensiva (UTI) no Brasil \\
\hline Lungen e Lapsley (2003) & Reembolso, pelo governo alemão, a hospitais de acordo com os DRG's \\
\hline Negrini et al (2004) & Metodologias de custeio hospitalares na Europa \\
\hline Waters e Hussey (2004) & $\begin{array}{l}\text { Revisão de metodologias e praticas de custeios em hospitais internacionais e } \\
\text { nos EUA }\end{array}$ \\
\hline $\begin{array}{l}\text { Larsen } \\
(2004)\end{array}$ & $\begin{array}{l}\text { Comparação entre os sistemas de custeio por Absorção com o ABC e o DRG } \\
\text { para o reembolso da terapêutica de pacientes com diagnóstico de angina } \\
\text { pectoris estável na Dinamarca }\end{array}$ \\
\hline Toyabea et al (2005) & $\begin{array}{l}\text { Proposta de um método para calcular os custos de materiais descartáveis } \\
\text { utilizados durante as cirurgias no Japão }\end{array}$ \\
\hline Raimundini et al (2005) & $\begin{array}{l}\text { Pesquisa bibliográfica com o objetivo de analisar os resultados apurados na } \\
\text { aplicação do custeio } \mathrm{ABC} \text { em hospitais e congêneres }\end{array}$ \\
\hline Jericó (2008) & $\begin{array}{l}\text { O ABC em um Centro de Material e Esterilização de um hospital de ensino em } \\
\text { São Paulo em conjunto com a aplicação da ABM }\end{array}$ \\
\hline Demeerec et al (2009) & $\begin{array}{l}\text { Time-driven activity-based costing (TDABC): nova abordagem para aplicação } \\
\text { do } \mathrm{ABC} \text { em ambulatórios na Bélgica }\end{array}$ \\
\hline Diez e Lennertz (2009) & $\begin{array}{l}\text { Custos de utilização da infra-estrutura comparados com o sistema de pagamento } \\
\text { por DER em hospitais na Alemanha }\end{array}$ \\
\hline Ramos e Miyake (2010) & $\begin{array}{l}\text { Proposta de método para a construção de indicadores hospitalares a partir da } \\
\text { abordagem sistêmica em São Paulo }\end{array}$ \\
\hline Ching (2010) & $\begin{array}{l}\text { Comparação entre sistemas tradicionais de custeio e o } \mathrm{ABC} \text { em hospitais no } \\
\text { Brasil }\end{array}$ \\
\hline Shander et al (2010) & $\begin{array}{l}\text { Uso do ABC para mensurar custos de transfusões sanguíneas em hospitais dos } \\
\text { Estados Unidos, Áustria e Suíça }\end{array}$ \\
\hline Souza et al (2008) & Análise do Sistema de Gestão de Custos de um Hospital Público no Brasil \\
\hline $\begin{array}{l}\text { St Hilaire e Crèpeau } \\
(2000)\end{array}$ & $\begin{array}{l}\text { Hospital and unit cost allocation methods. Estudo aborda os centros de custos } \\
\text { em hospitais europeus. }\end{array}$ \\
\hline Struett (2007) & $\begin{array}{l}\text { Aplicação do Custeio Baseado em Atividades: estudo de caso em um } \\
\text { laboratório de análises clínicas no Brasil }\end{array}$ \\
\hline
\end{tabular}




\section{METODOLOGIA}

\subsection{O Construto}

A presente pesquisa caracteriza-se como qualitativa por utilizar a abordagem sistêmica para tornar mais precisa a compreensão dos processos e atividades realizadas para a aplicação do custeamento $\mathrm{ABC}$ em todos os setores de um hospital privado. Quantitativa, pelo propósito de medir relações entre variáveis resultantes do custeamento com base na atividade. A Figura 2 ilustra o esquema metodológico utilizado para o desenvolvimento do trabalho. A partir de uma revisão das práticas de custeio em instituições hospitalares, nacionais e internacionais, foi estabelecido um balizamento inicial de variáveis e direcionadores adequados à aplicação do $\mathrm{ABC}$ na instituição escolhida. Para uma compreensão adequada das atividades e processos envolvidos foi adotada uma abordagem sistêmica. A AS propicia um conhecimento mais preciso de todos os setores envolvidos, suas interrelações e processos decisórios mais importantes; permite identificar as relações com o ambiente externo, representado pelas políticas de saúde, concorrência, fornecedores e usuários, dentre outras. Ademais, permite fixar os fluxos mais importantes de informações, materiais e serviços necessários para o custeamento com base na atividade. $\mathrm{O}$ critério para a escolha dos procedimentos cirúrgicos, objeto final de análise, para aplicação do $\mathrm{ABC}$, foi o de maior repercussão no faturamento do hospital. Com o custeamento $\mathrm{ABC}$ realizado e estabelecido os custos dos procedimentos cirúrgicos eleitos, foi realizada uma análise comparativa dos custos com a remuneração oferecida por cinco planos de saúde, incluindo-se o reembolso propiciado pelo Sistema Unificado de Saúde (SUS). 
Figura 2: Esquema Metodológico.

Fonte: Elaboração própria.

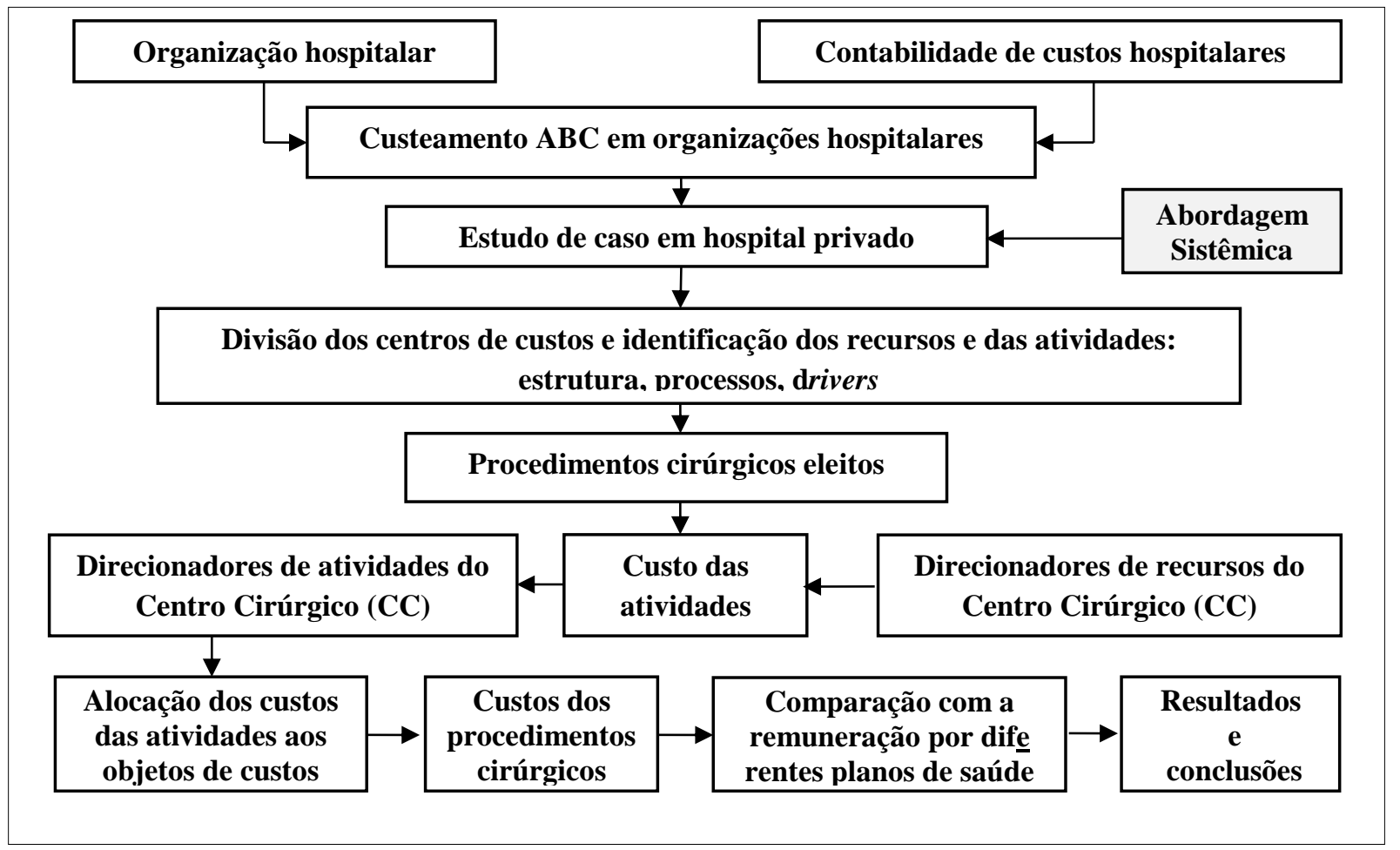

\subsection{A Abordagem Sistêmica}

Visto como um sistema complexo, o hospital possui necessidades entrantes para desenvolver seus processos, tais como informações, recursos financeiros, serviços técnicos. Para melhor compreensão do macro-processo hospitalar, este é fragmentado em centros de custos que, embora possuam atividades fins específicas, têm um objetivo comum que é o de promover a assistência à saúde aos pacientes, conforme ilustra a Figura 3. A elaboração de um modelo conceitual através da AS possibilita a visualização da interação existente entre as diferentes atividades desenvolvidas nos centros de custos, originando o construto do custeamento, pelo ABC. Ramos e Miyake (2010) utilizam a abordagem sistêmica para modelar a construção e implantação da gestão por processos, com o objetivo de propor um método para a contrução de um sistema de indicadores em hospitais. Relatam sobre a importância da identificação dos macro-processos, os quais retratam a missão de toda organização. Para os autores a gestão por processos, advinda da visão sistêmica nas instituições hospitalares, conduz ao aperfeiçoamento da qualidade dos serviços. 


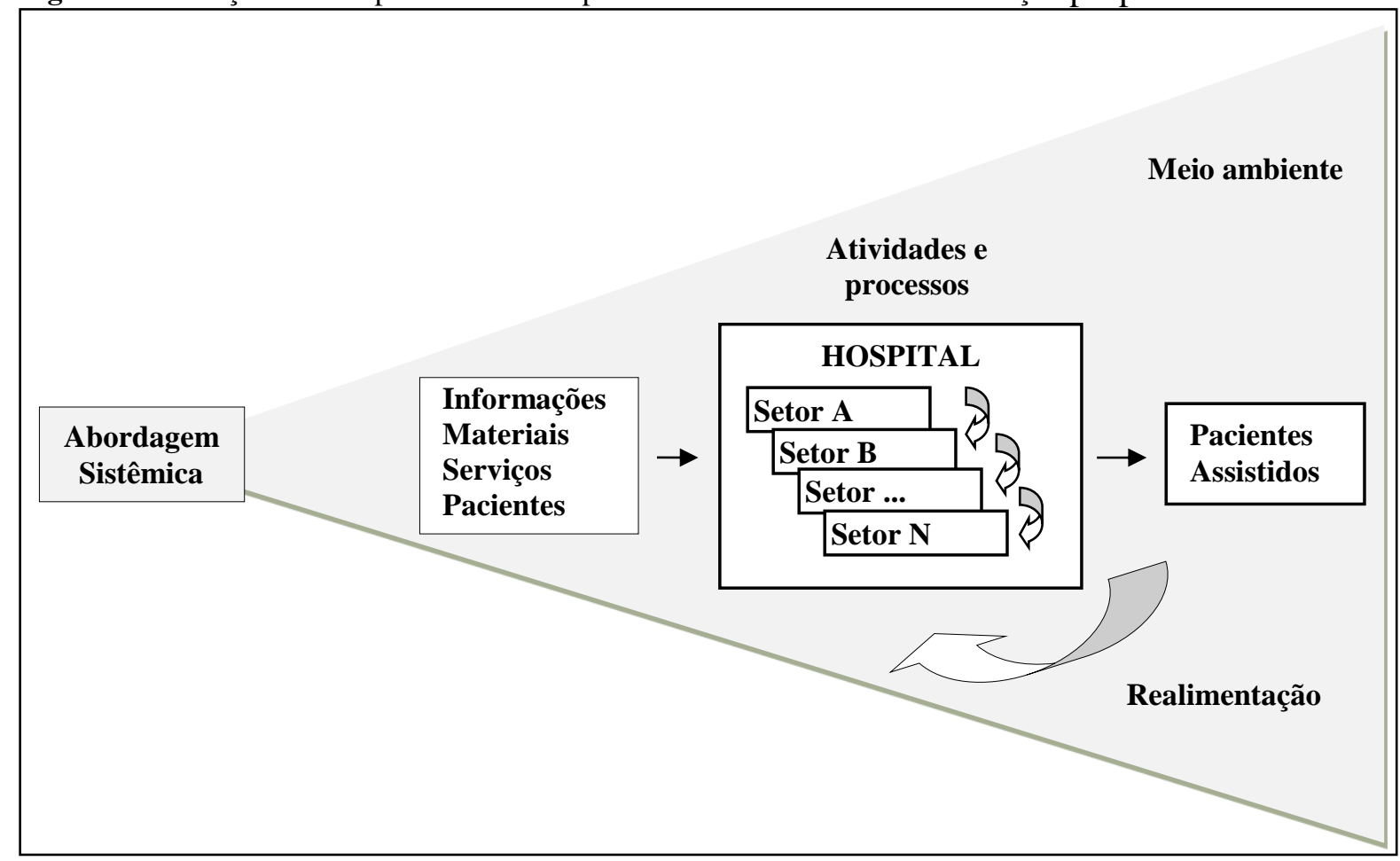

O estudo de caso desenvolvido no hospital tem como foco todos os centros de custos da instituição. O hospital já dispunha de uma base de dados estatísticos informatizada. Para realização da pesquisa contou-se com o apoio e o fornecimento de dados e documentos de todos os setores. A instituição hospitalar em estudo possui um manual de rotinas e serviços de acordo com as normas do sistema de avaliação e certificação da qualidade do Programa Brasileiro de Acreditação Hospitalar, desenvolvido pelo Ministério da Saúde (BRASIL, 2002).

$\mathrm{Na}$ abordagem para a determinação dos tempos de execução das atividades, optou-se por utilizar o tempo determinado pelos funcionários que as executam. Esta técnica foi aplicada por Ching (2010) em estudo de caso em uma maternidade. O foco da pesquisa está relacionado à execução das atividades por parte dos funcionários, o que para sua realização não exigiu interferir na execução dos serviços ou questionar os pacientes. Após a descrição e classificação dos centros de custos, ocorreu o levantamento dos recursos financeiros e dos dados não financeiros, por exemplo, despesas de pessoal, materiais e medicamentos, quilos de roupas processadas. Para o cálculo dos custos das atividades foi preciso, primeiramente, realizar o mapeamento dos processos internos pela AS para identificar as principais atividades 
desenvolvidas dentro do setor, conhecidos como objetos de custos que foram categorizados conforme a tipificação e a complexidade. Os recursos consumidos no setor foram então transferidos para as atividades através dos direcionadores. A seleção dos direcionadores considerou fatores como a facilidade na obtenção e a correlação entre esses e os recursos consumidos. Os direcionadores de recursos estão associados ao "consumo" de recursos pelas atividades e representam a quantidade de um recurso para a realização de uma atividade. Com a utilização dos direcionadores de custos foi realizada a alocação dos custos das atividades aos objetos, para todos os setores que consumem esta atividade. 


\section{RESULTADOS}

A abordagem sistêmica e o custeamento pelo ABC foram aplicados em todos os centros de custos do hospital em estudo. No subsistema centro cirúrgico (CC) foram identificados todos os fluxos de informações, materiais e serviços adequados ao seu funcionamento. A Figura 4 mostra esses fluxos, indicando os destinos das saídas e as origens de cada fluxo de entrada necessário. A coleta de dados financeiros e dados estatísticos do CC ocorreu entre os meses de janeiro a setembro de 2010; o conteúdo dados refere-se à base anual de maio de 2009 a junho de 2010. Os oito procedimentos cirúrgicos que mais contribuíram para a receita do hospital foram selecionados para custeamento e avaliação. Destarte, serão objetos finais do custeamento $\mathrm{ABC}$ : gastroplastia por videolaparoscopia, tratamento cirúrgico de varizes bilateral, colecistectomia com colangiografia por videolaparoscopia, herniorrafia inguinal bilateral, histerectomia total com anexectomia, apendicectomia, tireoidectomia total e postectomia.

Figura 4: Saídas e entradas do subsistema Centro Cirúrgico.

Fonte: Pesquisa.

\begin{tabular}{|c|c|c|c|}
\hline $\begin{array}{c}\text { UICl, UICi, } \\
\text { UTI, PA, } \\
\text { HEM }\end{array}$ & $\begin{array}{l}\text { Pacientes, prontuários e } \\
\text { solicitações de cirurgias }\end{array}$ & $\begin{array}{l}\text { Pacientes com cirurgias } \\
\text { realizadas e prontuários } \\
\text { com registros }\end{array}$ & $\begin{array}{l}\text { UICI, } \\
\text { UICi, } \\
\text { UTI }\end{array}$ \\
\hline CME & Materiais esterilizados & & \\
\hline FAR & Mat/medic. fracionados & $\begin{array}{l}\text { Instrumentais cirúrgicos } \\
\text { utilizados }\end{array}$ & CME \\
\hline NTI & Suporte técnico & & \\
\hline SADT & Laudos de exames & Enxoval utilizado & CPR \\
\hline ALM & Material de expediente & $\begin{array}{l}\text { Amostra de componentes } \\
\text { para análise }\end{array}$ & $\underline{\mathbf{L A B}}$ \\
\hline CPR & Enxoval cirúrgico limpo & & \\
\hline ADM & Água, energia, telefone & Relatórios gerenciais & DIR \\
\hline HIG & Limpeza e higienização & Lixo e demanda de & HIG \\
\hline MAN & $\begin{array}{l}\text { Manutenção preventiva } \\
\text { e/ou corretiva }\end{array}$ & higienização & \\
\hline \multicolumn{4}{|c|}{$\begin{array}{l}\text { UICl: unidade de internação clínica; UICi: unidade de internação cirúrgica; UTI: unidade de terapia } \\
\text { intensiva; PA: pronto atendimento; HEM: hemodinâmica; CME: central de material e esterilização; } \\
\text { FAR: farmácia; NTI: núcleo de tecnologia da informação; SADT: serviço de apoio de diagnóstico e } \\
\text { terapêutico; ALM: almoxarifado; CPR: centro de processamento de roupas; ADM: administração; } \\
\text { HIG: higienização e limpeza; MAN: manutenção; LAB: laboratório; DIR: diretoria. }\end{array}$} \\
\hline
\end{tabular}




\subsection{Atividades, Recursos e Direcionadores no Centro Cirúrgico}

O Centro Cirúrgico (CC) da instituição em estudo conta com quatro salas para a realização de procedimentos cirúrgicos, sala de recuperação pós-anestésica, vestiários feminino e masculino, sala de guarda de equipamentos, arsenal de materiais médicos e posto de enfermagem. Para que estas atividades possam ser executadas, o CC conta com uma equipe de higienização tecnicamente preparada para limpeza do ambiente, laps cirúrgicos e instrumentais estéreis vindos da CME, enxoval limpo oriundo do CPR, materiais médicos e medicamentos disponibilizados pela FAR e CAF, bem como os equipamentos e instalações sofrem manutenções preventivas e corretivas pela MAN. A Tabela 2 identifica as atividades realizadas no $\mathrm{CC}$.

Tabela 2: Identificação das atividades do Centro Cirúrgico.

Fonte: Fonte: Pesquisa.

\begin{tabular}{|c|c|}
\hline Atividades & Descrição \\
\hline $\begin{array}{l}\text { Admitir o paciente } \\
\text { na unidade }\end{array}$ & $\begin{array}{l}\text { Verificar tricotomia, confirmar o jejum a presença do prontuário; conferir o mapa de } \\
\text { cirurgias e verificar horário e sala para a realização; encaminhar o paciente e auxiliar } \\
\text { seu posicionamento na mesa de cirurgia; comunicar ao anestesista a chegada do } \\
\text { paciente }\end{array}$ \\
\hline $\begin{array}{l}\text { Preparar a sala } \\
\text { cirúrgica }\end{array}$ & $\begin{array}{l}\text { Colocar os pacotes estéreis com laps, instrumentais, materiais médicos, soluções e } \\
\text { medicamentos; dispor os instrumentais e outros materiais nas mesas auxiliares; } \\
\text { checar o foco e o aspirador }\end{array}$ \\
\hline $\begin{array}{l}\text { Anestesiar o } \\
\text { paciente }\end{array}$ & $\begin{array}{l}\text { Verificar qual procedimento será realizado e realizar a anestesia compatível com o } \\
\text { mesmo (raque, peridural ou geral) }\end{array}$ \\
\hline $\begin{array}{l}\text { Realizar o ato } \\
\text { cirúrgico }\end{array}$ & A equipe médica, não contratada, realiza a cirurgia conforme diagnóstico \\
\hline $\begin{array}{l}\text { Auxiliar no ato } \\
\text { cirúrgico }\end{array}$ & $\begin{array}{l}\text { Compete a equipe de enfermagem o auxílio aos cirurgiões, durante o ato operatório, } \\
\text { monitorando a sala ou instrumentando para o cirurgião até o término do procedimento, } \\
\text { quando o paciente é encaminhado para a recuperação pós-anestésica }\end{array}$ \\
\hline $\begin{array}{l}\text { Assistir ao paciente } \\
\text { na recuperação } \\
\text { anestésica }\end{array}$ & Monitorar o paciente, pós-anestesia \\
\hline $\begin{array}{l}\text { Encaminhar o } \\
\text { paciente a unidade } \\
\text { de internação }\end{array}$ & $\begin{array}{l}\text { Contatar a unidade de internação, solicitar sua remoção, orientar a enfermagem quanto a } \\
\text { possíveis drenos, sondas e cuidados imediatos, entregar o prontuário com os registros } \\
\text { médicos e da equipe de enfermagem }\end{array}$ \\
\hline $\begin{array}{l}\text { Preparar a sala para } \\
\text { a próxima cirurgia }\end{array}$ & $\begin{array}{l}\text { Recolher os instrumentais utilizados e encaminhá-los ao expurgo da CME; acondicionar } \\
\text { compressas, gazes, roupas em hamper identificado (setor e roupas contaminadas); } \\
\text { guardar material médico e medicamentos não utilizados; remover para o arsenal os } \\
\text { pacotes estéreis não utilizados; recolher o lixo e realizar a limpeza e desinfecção da sala }\end{array}$ \\
\hline Gerenciar o setor & Gerenciamento do setor \\
\hline
\end{tabular}


Os recursos despendidos de outros centros de custos são resultados da análise feita pela abordagem sistêmica e do custeamento pelo ABC nas unidades hospitalares que prestam serviços para o centro cirúrgico. Portanto, possuem parte de suas despesas rateadas para este setor. A Tabela 3 mostra os recursos necessários ao desenvolvimento das atividades do centro cirúrgico. Os valores foram apreendidos de registros do histórico das atividades.

O CC possui um custo para desenvolverem suas atividades composto por desembolso direto e por recursos despendidos de outras unidades. A soma destes recursos será alocada para as atividades conforme o consumo, pelos direcionadores de recursos tempo (em minutos), alocação direta e estimativa gerencial, formando o custo de cada atividade. O tempo para se realizar as atividades foi mensurado pelos funcionários das unidades; a alocação do custo da energia elétrica gasta para realizar as atividades foi estimada levando-se em consideração a potência e o consumo dos equipamentos. Outras estimativas gerenciais foram consideradas levando-se em conta a expertise dos gestores.

Tabela 3: Recursos financeiros do Centro Cirúrgico.

Fonte: Fonte: Pesquisa.

\begin{tabular}{|c|c|c|}
\hline \multicolumn{2}{|l|}{ Recursos } & Valor $(\mathrm{R} \$)$ \\
\hline \multicolumn{2}{|l|}{ Recursos próprios do setor: } & \\
\hline \multicolumn{2}{|l|}{ Pessoal } & $60.539,44$ \\
\hline \multicolumn{2}{|l|}{ Material de consumo } & 884,07 \\
\hline \multicolumn{2}{|l|}{ Material médico hospitalar } & $2.431,00$ \\
\hline \multicolumn{2}{|l|}{ Energia elétrica } & $2.996,00$ \\
\hline \multicolumn{2}{|l|}{ Telefone } & 263,45 \\
\hline \multicolumn{2}{|l|}{ Recursos despendidos de outros setores: } & \multirow{8}{*}{$43.121,93$} \\
\hline Higienização (HIG) & $24.768,50$ & \\
\hline Almoxarifado (ALM) & 198,82 & \\
\hline Diretoria (DIR) & $10.525,38$ & \\
\hline Manutenção (MAN) & $2.826,47$ & \\
\hline Núcleo Tecnologia Informação (NTI) & 287,16 & \\
\hline Recursos Humanos (RH) & 549,22 & \\
\hline Serviço Nutrição Dietética (SND) & $3.966,38$ & \\
\hline Central Material Esterilização (CME) & $32.019,98$ & \multirow{3}{*}{$44.897,28$} \\
\hline Centro Processamento Roupas (CPR) & $9.924,11$ & \\
\hline Farmácia (FAR) & $2.863,19$ & \\
\hline
\end{tabular}

Nota: os honorários médicos dos cirurgiões são pagos diretamente pela operadora do plano de saúde e não estão contemplados neste segmento. $\mathrm{Na}$ despesa com pessoal estão inclusos apenas os gastos salariais dos médicos 
anestesistas, equipe de enfermagem e funcionários que atuam na área administrativa, contratados pela instituição.

Os objetos de custos (cirurgias) consomem as atividades realizadas; seu custeamento é baseado nos direcionadores de atividades: tempo para a realização de cada procedimento, número de cirurgias realizadas e tipo de anestesia utilizada. A Figura 5 apresenta, esquematicamente, a utilização dos direcionadores para a formação dos custos das atividades que formam os procedimentos cirúrgicos.

Figura 5: Utilização dos direcionadores na formação dos custos das cirurgias. Fonte: Elaboração própria.

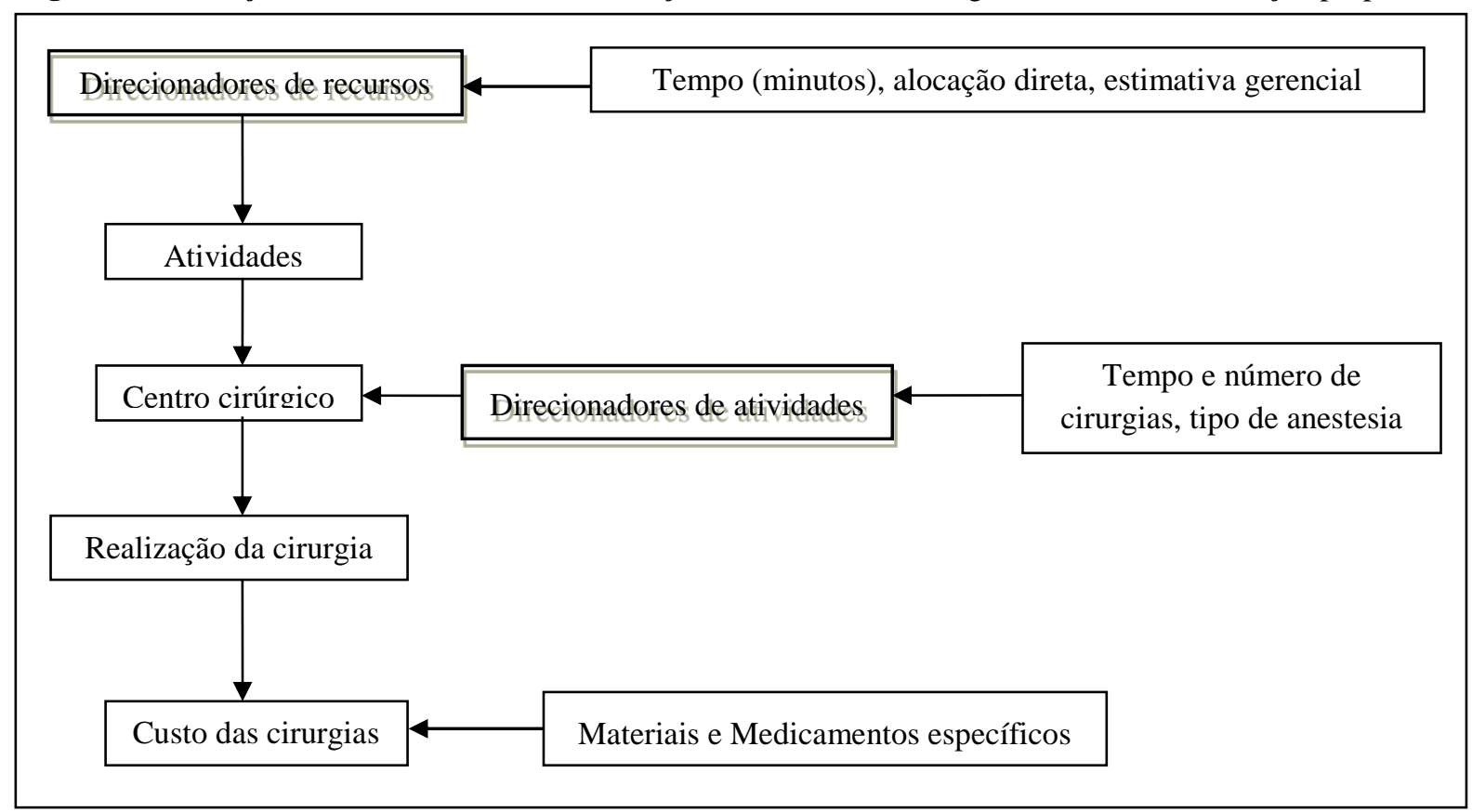

A Tabela 4 indica os direcionadores de recursos utilizados para alocar os recursos consumidos pelas atividades do CC.

Tabela 4: Direcionadores de recursos do Centro Cirúrgico.

Fonte: Pesquisa.

\begin{tabular}{l|c}
\hline \multicolumn{1}{c|}{ Recursos } & Direcionadores de recursos \\
\hline \hline Pessoal & Tempo em minutos \\
\hline Material de consumo & Estimativa gerencial \\
\hline Material médico & Estimativa gerencial \\
\hline Energia elétrica & Estimativa gerencial \\
\hline Telefone & Alocação direta \\
\hline Recursos recebidos CME, CPR e FAR & Tempo em minutos \\
\hline Recursos despendidos de outros setores & \\
\hline
\end{tabular}


A Tabela 5 mostra a alocação dos recursos financeiros às atividades internas do $\mathrm{CC}$ de acordo com os direcionadores dos recursos.

Tabela 5: Recursos financeiros consumidos por atividades no CC.

Fonte: Pesquisa.

\begin{tabular}{|c|c|c|c|c|}
\hline Recursos & $\begin{array}{c}\text { Direcionadores } \\
\text { de recursos }\end{array}$ & $\begin{array}{l}\text { Recursos } \\
\text { financeiros }\end{array}$ & Atividades & $\%$ \\
\hline \multirow{8}{*}{ Pessoal } & \multirow{8}{*}{$\begin{array}{l}\text { Tempo em } \\
\text { minutos }\end{array}$} & $3.632,37$ & Admitir o paciente na unidade & 6 \\
\hline & & $5.448,55$ & Preparar a sala cirúrgica & 9 \\
\hline & & $6.053,94$ & Anestesiar o paciente & 10 \\
\hline & & $23.004,99$ & Auxiliar no ato cirúrgico & 38 \\
\hline & & $5.448,55$ & Assistir paciente na recuperação anestésica & 9 \\
\hline & & $4.237,76$ & $\begin{array}{l}\text { Encaminhar o paciente a unidade de } \\
\text { internação }\end{array}$ & 7 \\
\hline & & $7.870,13$ & Preparar a sala para a próxima cirurgia & 13 \\
\hline & & $4.843,16$ & Gerenciar o setor & 8 \\
\hline Material de consumo & Estimativa & 884,07 & Gerenciar o setor & 100 \\
\hline \multirow{4}{*}{ Material médico } & \multirow{4}{*}{ Estimativa } & 170,17 & Preparar a sala cirúrgica & 7 \\
\hline & & $1.969,11$ & Anestesiar o paciente & 81 \\
\hline & & 121,55 & Encaminhar paciente à unid de internação & 5 \\
\hline & & 170,17 & Preparar a sala para a próxima cirurgia & 7 \\
\hline \multirow{5}{*}{ Energia elétrica } & \multirow{5}{*}{ Estimativa } & 599,20 & Preparar a sala cirúrgica & 20 \\
\hline & & 599,20 & Anestesiar o paciente & 20 \\
\hline & & 599,20 & Encaminhar paciente à unid.de internação & 20 \\
\hline & & 599,20 & Preparar a sala para a próxima cirurgia & 20 \\
\hline & & 599,20 & Gerenciar o setor & 20 \\
\hline Telefone & Estimativa & 263,45 & Gerenciar o setor & 100 \\
\hline $\begin{array}{l}\text { Recursos oriundos da } \\
\text { CME, CPR, FAR }\end{array}$ & Alocação direta & $44.807,28$ & Realizar o ato cirúrgico & 100 \\
\hline \multirow{8}{*}{$\begin{array}{l}\text { Recursos despendidos de } \\
\text { outros setores }\end{array}$} & \multirow{8}{*}{$\begin{array}{l}\text { Tempo em } \\
\text { minutos }\end{array}$} & $2.587,32$ & Admitir o paciente na unidade & 6 \\
\hline & & $3.880,97$ & Preparar a sala cirúrgica & 9 \\
\hline & & $4.312,19$ & Anestesiar o paciente & 10 \\
\hline & & $16.386,33$ & Auxiliar no ato cirúrgico & 38 \\
\hline & & $3.880,97$ & Assistir paciente na recuperação anestésica & 9 \\
\hline & & $3.018,54$ & Encaminhar paciente à unid. de internação & 7 \\
\hline & & $5.605,85$ & Preparar a sala para a próxima cirurgia & 13 \\
\hline & & $3.449,75$ & Gerenciar o setor & 8 \\
\hline
\end{tabular}


Por outro lado, a Tabela 6 consolida os custos por atividade interna do centro cirúrgico. Importante observar que o custo total apresentado refere-se ao valor de todas as atividades necessárias para a realização de todos os procedimentos cirúrgicos do período. Portanto, apenas parcelas desses valores serão apropriadas as oito cirurgias eleitas para custeio.

Tabela 6: Custos para realizar as atividades no Centro Cirúrgico.

Fonte: Pesquisa.

\begin{tabular}{l|c}
\hline \multicolumn{1}{c|}{ Atividade } & Recurso financeiro \\
\hline \hline Admitir o paciente na unidade & $6.219,68$ \\
\hline Preparar a sala cirúrgica & $10.098,89$ \\
\hline Anestesiar o paciente & $12.934,45$ \\
\hline Auxiliar no ato cirúrgico & $39.391,32$ \\
\hline Realizar o ato cirúrgico & $44.807,28$ \\
\hline Assistir ao paciente na recuperação anestésica & $9.329,52$ \\
\hline Encaminhar o paciente a unidade de internação & $7.977,05$ \\
\hline Preparar a sala para a próxima cirurgia & $14.245,35$ \\
\hline Gerenciar o setor $\quad$ Total & $\mathbf{1 0 . 0 3 9 , 6 3}$ \\
\hline
\end{tabular}

No centro cirúrgico são realizados diversos tipos de cirurgias, divididas por especialidades médicas. Em média, são 424 procedimentos/mês sendo identificado que o objeto de custos da unidade é a realização de cirurgias. Para realizar a alocação dos custos das atividades desenvolvidas no centro cirúrgico ao objeto de custo, os aspectos tempo de execução do procedimento cirúrgico, o tipo de anestesia empregada e o tempo de recuperação pós-anestésica foram considerados. O direcionador de recurso tempo foi obtido através do tempo médio em minutos, para realizar todas as atividades, conforme Tabela 7. 
Tabela 7: Atividades com custos direcionados pelo tempo.

Fonte: Pesquisa.

\begin{tabular}{l|c|c|c|c}
\hline \multicolumn{1}{c|}{ Atividade } & $\begin{array}{c}\text { Tempo médio } \\
\text { (minutos) }\end{array}$ & $\begin{array}{c}\text { Número de } \\
\text { cirurgias }\end{array}$ & $\begin{array}{c}\text { Tempo } \\
\text { total }\end{array}$ & $\begin{array}{c}\text { Custo total } \\
\text { da atividade }\end{array}$ \\
\hline \hline Anestesiar o paciente & 12 & 424 & 5.088 & $12.934,45$ \\
\hline Auxiliar no ato cirúrgico & 90 & 424 & 38.160 & $39.391,32$ \\
\hline Assistir paciente recuperação anestésica & 15 & 424 & 6.360 & $9.329,52$ \\
\hline Encaminhar paciente unidade internação & 15 & 424 & 6.360 & $7.977,05$ \\
\hline Gerenciar o setor & 10 & 424 & 4.240 & $10.039,63$ \\
\hline Total & & & 60.208 & $79.671,97$ \\
\hline Custo unitário (R\$minuto) & & & & 1,32 \\
\hline
\end{tabular}

A alocação dos custos variáveis das atividades do CC é então obtida pela multiplicação do tempo médio para realizar todas as atividades que envolvem as cirurgias pelo custo unitário ( $\mathrm{R} \$ /$ minuto), exposto na Tabela 8 . O tempo médio, em minutos, para se realizar cada atividade foi obtido por amostragem, num período de quatro semanas. Entendese como tempo de cirurgia o período correspondente da primeira incisão até a última sutura.

Tabela 8: Alocação dos custos variáveis das atividades no CC.

Fonte: Pesquisa.

\begin{tabular}{l|c|c|c}
\hline \hline \multicolumn{1}{|c|}{ Cirurgia } & Tempo Médio & Custo unitário & Custo total \\
\hline \hline 1.Gastroplastia & 167 & 1,32 & 220,44 \\
\hline 2.Varizes & 122 & 1,32 & 161,04 \\
\hline 3.Colecistectomia & 157 & 1,32 & 207,24 \\
\hline 4.Herniorrafia & 112 & 1,32 & 147,84 \\
\hline 5.Histerectomia & 142 & 1,32 & 187,44 \\
\hline 6.Apendicectomia & 122 & 1,32 & 161,04 \\
\hline 7.Tireoidectomia & 107 & 1,32 & 95,04 \\
\hline 8.Postectomia & 72 & 1,32 & 1,24 \\
\hline
\end{tabular}

O custo fixo unitário de cada atividade comum às cirurgias realizadas foi obtido conforme exposto na Tabela 9. 
Tabela 9: Atividades com custo fixo direcionado por número de cirurgias.

Fonte: Pesquisa.

\begin{tabular}{l|c|c|c}
\hline \hline \multicolumn{1}{c|}{ Atividade } & $\begin{array}{c}\text { Número de } \\
\text { cirurgias }\end{array}$ & $\begin{array}{c}\text { Custo total } \\
\text { da atividade }\end{array}$ & $\begin{array}{c}\text { Custo unitário } \\
\text { R \$cirurgia }\end{array}$ \\
\hline \hline Admitir o paciente na unidade & 424 & $6.219,68$ & 14,67 \\
\hline Preparar a sala cirúrgica & 424 & $10.098,89$ & 23,82 \\
\hline Realizar o ato cirúrgico & 424 & $44.807,28$ & 33,60 \\
\hline Preparar sala para próxima cirurgia & 424 & $14.245,35$ & 177,77 \\
\hline Total & 424 & $75.371,20$ & \\
\hline
\end{tabular}

O cálculo do custo da anestesia foi feito de acordo com a técnica empregada; levou-se em consideração o valor médio dos anestésicos utilizados no período da coleta de dados, de acordo com o tipo de anestesia aplicada (Tabela 10).

Tabela 10: Alocação dos anestésicos no CC.

Fonte: Pesquisa.

\begin{tabular}{l|c|c|c}
\hline \multicolumn{1}{c|}{ Tipo de anestesia } & Número de cirurgias & Valor dos anestésicos & Custo unitário por anestesia \\
\hline \hline Local & 38 & $1.127,00$ & 29,66 \\
\hline Raque & 123 & $3.894,00$ & 31,66 \\
\hline Peridural & 118 & $5.737,27$ & 48,62 \\
\hline Geral & 145 & $14.891,55$ & 102,70 \\
\hline
\end{tabular}

\subsection{Custos e Remuneração das Cirurgias Selecionadas}

Uma importante questão colocada para os gestores hospitalares é saber em que medida os valores reembolsados pelos diferentes planos de saúde remuneram os seus custos. Visto por outro ângulo, recai-se na clássica questão do apreçamento. Quanto deveria o hospital cobrar por cada um dos procedimentos cirúrgicos? A análise aqui empreendida faz uma comparação dos custos básicos estabelecidos pelo custeamento $\mathrm{ABC}$ com a remuneração oferecida por quatro diferentes planos de saúde. Foram escolhidos cinco planos, representando cinco diferentes níveis de remuneração. A mais baixa remuneração corresponde ao reembolso praticado pelo plano público SUS. Os demais foram selecionados dentre aqueles registrados pela Agência Nacional de Saúde (ANS). Dos quatro planos privados, três atuam nacionalmente e estão dentre os cinco maiores em clientela no Brasil. O quarto é um plano regional com valores de cobertura menor e com atuação em alguns Estados da Federação. 
O custo total unitário de cada cirurgia é obtido pela soma de quatro parcelas: (1) custo da atividade direcionada pelo tempo da cirurgia; (2) custo da atividade direcionada por cirurgia; (3) custo dos anestésicos (materiais e medicamentos); e, (4) do custo com materiais e medicamentos específicos de cada cirurgia. Os tempos médios para realização das oito cirurgias selecionadas e os respectivos custos das atividades direcionadas pelo tempo são apresentados na Tabela 11.

Tabela 11: Alocação dos custos das atividades no CC.

Fonte: Pesquisa.

\begin{tabular}{l|c|c|c|c|c|c}
\hline \hline \multicolumn{1}{c|}{ Cirurgia } & $\begin{array}{c}\text { 1. Custo da } \\
\text { atividade } \\
\text { (variável) }\end{array}$ & $\begin{array}{c}\text { 2. Custo da } \\
\text { atividade } \\
\text { (fixo) }\end{array}$ & $\begin{array}{c}\text { 3. Custo } \\
\text { dos } \\
\text { anestésicos }\end{array}$ & $\begin{array}{c}\text { 4. Custo dos } \\
\text { materiais e } \\
\text { medicamentos }\end{array}$ & $\begin{array}{c}\text { Custo total } \\
\text { unitário da } \\
\text { cirurgia }\end{array}$ & $\begin{array}{c}\text { Participação } \\
\text { na receita } \\
(\%)\end{array}$ \\
\hline \hline 1.Gastroplastia & 220,44 & 177,77 & 102,70 & $9.171,25$ & $9.672,16$ & 20,12 \\
\hline 2.Varizes & 161,04 & 177,77 & 31,66 & 544,82 & 915,29 & 3,19 \\
\hline 3.Colecistectomia & 207,24 & 177,77 & 48,62 & 324,67 & 758,30 & 1,63 \\
\hline 4.Herniorrafia & 147,84 & 177,77 & 102,70 & 233,87 & 662,18 & 1,06 \\
\hline 5.Histerectomia & 187,44 & 177,77 & 102,70 & 249,18 & 717,9 & 0,94 \\
\hline 6.Apendicectomia & 161,04 & 177,77 & 102,70 & 355,62 & 797,13 & 1,32 \\
\hline 7.Tireoidectomia & 141,24 & 177,77 & 102,70 & 182,05 & 603,76 & 1,96 \\
\hline 8.Postectomia & 95,04 & 177,77 & 29,66 & 104,13 & 406,60 & 0,49 \\
\hline
\end{tabular}

A cirurgia que possui a maior representação percentual na receita gerada pelo centro cirúrgico é a gastroplastia com $20,12 \%$ do total, em seguida, o tratamento de varizes bilateral com 3,19\%. O restante é distribuído entre os demais procedimentos. Após a alta do paciente da recuperação pós-anestésica, pelo anestesista, o paciente é transferido para a unidade de internação cirúrgica (UICi) ou para a UTI de acordo com a orientação médica.

Os valores de reembolso dos planos de saúde, apresentados na Tabela 12, foram coletados diretamente das tabelas de remuneração oferecidas pelos planos no mês de março de 2011, nas respectivas cirurgias. Os valores não incluem as diárias de internação. Tratando-se de serviços, a incidência de impostos sobre os valores da receita gerada pelo reembolso das cirurgias é de $8,65 \%$, correspondente a $5 \%$ de ISS, $0,65 \%$ de PIS e $3 \%$ de COFINS. Nesta comparação, o imposto de renda e a contribuição social não foram considerados por incidirem apenas nos resultados após apuração do lucro real anual. A Tabela 12 mostra o custo final ABC apurado para cada cirurgia e as diferenças percentuais entre os valores líquidos, 
deduzidos os impostos, reembolsados pelos cinco planos. Os valores estão em reais e foram arredondados.

Tabela 12: Comparação do custo $\mathrm{ABC}$ com valores reembolsados pelos planos. Fonte: Pesquisa.

\begin{tabular}{l|c|c|c|c|c|c|c|c|c|c|c}
\hline \hline \multicolumn{1}{c|}{ Cirurgia } & $\begin{array}{c}\text { Custo } \\
\text { ABC }\end{array}$ & $\begin{array}{c}\text { Plano } \\
\text { A }\end{array}$ & $\begin{array}{c}\text { Dif. } \\
(\%)\end{array}$ & $\begin{array}{c}\text { Plano } \\
\text { B }\end{array}$ & $\begin{array}{c}\text { Dif. } \\
(\%)\end{array}$ & $\begin{array}{c}\text { Plano } \\
\text { C }\end{array}$ & $\begin{array}{c}\text { Dif. } \\
(\%)\end{array}$ & $\begin{array}{c}\text { Plano } \\
\text { D }\end{array}$ & $\begin{array}{c}\text { Dif. } \\
(\%)\end{array}$ & $\begin{array}{c}\text { Plano } \\
\text { E }\end{array}$ & Dif. $(\%)$ \\
\hline \hline 1.Gastroplastia & 9.672 & 9.211 & $\mathbf{- 4 , 7 7}$ & 7.056 & $\mathbf{- 2 7 , 0 5}$ & 7.022 & $\mathbf{- 2 7 , 4 0}$ & 10.993 & 13,65 & 5.179 & $\mathbf{- 4 6 , 4 5}$ \\
\hline 2.Varizes & 915 & 858 & $\mathbf{- 6 , 2 7}$ & 735 & $\mathbf{- 1 9 , 7 2}$ & 704 & $\mathbf{- 2 3 , 1 2}$ & 953 & 4,11 & 324 & $\mathbf{- 6 4 , 6 3}$ \\
\hline 3.Colecistectomia & 758 & 792 & 4,49 & 491 & $\mathbf{- 3 5 , 2 8}$ & 1.148 & 51,39 & 999 & 31,74 & 693 & $\mathbf{- 8 , 6 0}$ \\
\hline 4.Herniorrafia & 662 & 437 & $\mathbf{- 3 4 , 0 4}$ & 779 & 17,68 & 680 & 2,72 & 683 & 3,11 & 426 & $\mathbf{- 3 5 , 6 6}$ \\
\hline 5.Histerectomia & 718 & 584 & $\mathbf{- 1 8 , 5 9}$ & 1.028 & 43,16 & 981 & 36,67 & 736 & 2,49 & 487 & $\mathbf{- 3 2 , 1 5}$ \\
\hline 6.Apendicectomia & 797 & 693 & $\mathbf{- 1 3 , 0 8}$ & 493 & $\mathbf{- 3 8 , 1 2}$ & 827 & 3,69 & 734 & $\mathbf{- 7 , 9 6}$ & 445 & $\mathbf{- 4 4 , 2 2}$ \\
\hline 7.Tireoidectomia & 604 & 528 & $\mathbf{- 1 2 , 5 1}$ & 763 & 26,46 & 806 & 33,54 & 701 & 16,09 & 450 & $\mathbf{- 2 5 , 5}$ \\
\hline 8.Postectomia & 407 & 306 & $\mathbf{- 2 4 , 6 2}$ & 372 & $\mathbf{- 8 , 4 2}$ & 351 & $\mathbf{- 1 3 , 6 0}$ & 425 & 4,48 & 219 & $\mathbf{- 4 6 , 1 1}$ \\
\hline
\end{tabular}

Comparando os resultados obtidos com o custo apurado observa-se defasagem significativa entre a remuneração dos planos. O plano que mais se aproxima da cobertura mínima desejada dos custos das cirurgias é o Plano D apresentando, inclusive uma diferença de $13,64 \%$ à maior para a remuneração na gastroplastia, procedimento que mais contribui para a receita gerada. Embora apresente resultados positivos em cinco procedimentos, o Plano C apresenta resultados deficitários em três cirurgias, incluindo os dois procedimentos que mais contribuem para a formação da renda do hospital, a gastroplastia pelo valor e a cirurgia de varizes pelo número realizado.

A perda de receita do hospital quando realizados os procedimentos 1, 2, 3, 6 e 8 pelo Plano B, respectivamente corresponde a $-27,05,-19,72,-35,28,-38,12$ e $-8,42 \%$. O Plano A é o que mais recebe faturas do hospital em estudo; o comparativo entre a remuneração realizada e a perda refletida nos rendimentos é demonstrado em quase todas as cirurgias, exceto para a colecistectomia. A gastroplastia apresenta a menor diferença percentual negativa, porém este procedimento é o que possui o maior custo dentre as cirurgias estudadas tornando-se considerável o reflexo de $4,77 \%$ a menor para a remuneração. Finalizando, o Plano E, convênio SUS, é o que fornece a menor cobertura para os custos das cirurgias no hospital e reflete perda em qualquer uma das cirurgias custeadas.

O aumento no custo dos insumos, dificuldades na captação de recursos e investimentos sempre necessários geram impactos na formação dos custos dos procedimentos 
cirúrgicos. A necessidade de constantes análises de custos de cirurgias com a comparação entre as remunerações realizadas por diferentes planos de saúde podem oferecer bases importantes no processo decisório das organizações hospitalares. 


\section{CONCLUSÕES}

A peculiaridade e a complexidade das atividades desenvolvidas no âmbito hospitalar acarretam em certa dificuldade de identificar os insumos, serviços e informações necessárias para a realização dos serviços que culminam com a atenção à saúde do paciente. O uso da abordagem sistêmica (AS) mostrou ser um método facilitador na identificação das interrelações de processos permitindo fixar os fluxos mais relevantes de informações, materiais e serviços imprescindíveis para o custeamento com base na atividade. A abordagem sistêmica (AS) contribuiu positivamente na construção do custeio com base no $\mathrm{ABC}$ na instituição hospitalar de saúde suplementar. A partir do seu desenvolvimento, houve maior clareza na identificação dos recursos necessários para a realização de procedimentos cirúrgicos. $\mathrm{O}$ ABC pôde ser aplicado com maior facilidade devido à melhor identificação das atividades e recursos necessários para mensurar os custos das cirurgias possibilitando a comparação entre as remunerações realizadas por diferentes planos de saúde. A importância do estudo reside na clareza advinda da aplicação em conjunto da $\mathrm{AS}$ e do $\mathrm{ABC}$ proporcionando maior facilidade e eficiência para o custeio em toda organização.

$\mathrm{O}$ custeamento pelo $\mathrm{ABC}$ tem apresentado importantes contribuições no que se refere à identificação correta e precisa das alocações dos custos indiretos às atividades desenvolvidas em cada setor hospitalar. $\mathrm{O}$ custeio pelo $\mathrm{ABC}$ oportunizou a identificação das atividades que consomem os recursos do centro cirúrgico e identificou os fatores básicos que afetam os custos hospitalares e as forças que controlam esses fatores. Constitui-se numa ferramenta estratégica para ação gerencial; não só para monitorar o custeio intersetorial, como também para definir linhas de ação gerencial mais abrangente, possibilitando a identificação de caminhos estratégicos para as organizações. Conhecer o custo de cada serviço que compõem os procedimentos cirúrgicos torna a instituição competitiva no mercado.

A possibilidade de comparação entre os custos reais dos procedimentos cirúrgicos com as remunerações realizadas por diferentes planos de saúde permite não só o questionamento sobre as vantagens e desvantagens de se estreitar as relações comerciais com cada plano, como comporta o estabelecimento de avaliações internas de desempenho, buscando aprimorar processos relevantes que repercutam na cadeia de valor da organização. Nos oito procedimentos cirúrgicos, os valores reembolsados pelo sistema público SUS ficam abaixo dos valores $A B C$ custeados, variando de $-64,63 \%$ na cirurgia de varizes a $-8,60$ na colecistectomia. Sem incluir o SUS, a magnitude das variações entre máximos e mínimos 
dentre os valores reembolsados pelos planos, em cada tipo de cirurgia, chama a atenção. $\mathrm{Na}$ colecistectomia, a variação foi de 86,67\%, mínimo de -35,28\% (Plano B) e máximo de $51,39 \%$ (Plano C). Mesmo quando a comparação é realizada entre os grandes planos nacionais, no caso A, B e D, as variações entre reembolsos são acentuadas. No caso da herniorrafia inguinal, o máximo foi o reembolso do plano B com 17,68\% e o mínimo do plano A com $-34,04 \%$, perfazendo uma variação total em torno do custo $\mathrm{ABC}$ de $51,72 \%$. Os resultados sugerem que os planos de saúde nacionais trabalham com metodologias não convergentes na formação de suas tabelas de remuneração. Os resultados possibilitam o aprimoramento da gestão dos recursos e uma análise do impacto dos reembolsos propiciados pelas diferentes tabelas dos planos médicos credenciados.

A apropriação do consumo de material médico e medicamentos valeu-se dos valores pré-estabelecidos nos pacotes adotados pelos planos de saúde, não sendo consideradas as peculiaridades de cada caso. Outra limitação diz respeito às possíveis ineficiências operacionais e gerenciais da organização avaliada; não houve questionamento sobre eficiência e produtividade de suas operações. Os valores apropriados foram correspondentes a prática existente. Sem embargo, as informações sobre os custos hospitalares são de grande valia para a tomada de decisão dos gestores e para o controle interno das operações. Trabalhos dessa natureza possibilitam o aprimoramento de métodos de custeios que atendam às necessidades de obtenção de informações cada vez mais precisas, propiciando a redução dos custos e melhorando o aproveitamento dos recursos. 


\section{REFERÊNCIAS}

ABBAS, K. Gestão de custos em organizações hospitalares. 2001. Dissertação (Mestrado Engenharia de Produção) - Universidade Federal de Santa Catarina, Florianópolis, 2001.

BOISVERT, H. Contabilidade por atividades: contabilidade de gestão, práticas avançadas. Tradução de: Antônio Diomário de Queiroz. São Paulo: Atlas, 1999.

BRASIL. Ministério da Saúde. Manual Brasileiro de Acreditação Hospitalar. Brasília: Secretaria de Assistência à Saúde, 2002.

CHING, H. Y. Manual de custos de instituições de saúde: sistemas tradicionais de custos e sistema baseado em atividades (ABC). 2 ed. São Paulo: Atlas, 2010.

DEMEEREC, N.; STOUTHUYSENA, K.; ROODHOOFT, F. Time-driven activity-based costing in an outpatient clinic environment: Development, relevance and managerial impact. Health Policy, v. 92, p. 296-304, 2009.

DIEZ, K.; LENNERTZ, K. A process-oriented analysis of facility management services in hospitals as a basis for strategic planning. Journal of Facilities Management. v. 7, n. 1, 2009.

FALK, J. A. Gestão de Custos para Hospitais, São Paulo: Atlas, 2001.

JACOBS, P.; FINLAYSON, G.; FAIENZA, B.; BROWN, M.; NEWSON, B; Mc LEAN, N. "The development of a tool to assess quality of cost estimate". Disease Management \& Health Outcomes. v. 10, n. 2, p. 127-32, 2002.

JERICÓ, M. C. Aplicação do Custeio Baseado em Atividades em Centro de Material Esterilizado. Tese (Doutorado em Enfermagem) - Programa de Pós-Graduação da Escola de Enfermagem de São Paulo da Universidade de São Paulo, São Paulo, 2008.

KAPLAN, R. S.; ANDERSON, S. The innovation of time-driven activity-based costing. Journal of Cost Management, v. 21, p. 5-15, 2007.

KAPLAN, R. S.; COOPER, R. Custo \& desempenho: administre seus custos para ser mais competitivo. Trad. O. P. Traduções. São Paulo: Futura, 1998.

LARSEN, J.; SKJOLDBORG, U. S. Comparing systems for costing hospital treatments: The case of stable angina pectoris. Health Policy, v. 67, p. 293-307, 2004.

LUNGEN, M.; LAPSLEY, I. The reform of hospital financing in Germany: an international solution? Journal of Health Organization and Management. Germany, v. 17, n. 5, 2003. MARTINS, D. S. Custeio Hospitalar por Atividades: Activity Based Costing. São Paulo: Atlas, 2002.

MARTINS, E. Contabilidade de custos. São Paulo: Atlas, 2003. 
MATOS, A. J. Gestão de custos hospitalares: técnicas, análise e tomada de decisão. São Paulo: Editora STS, 2002.

NAKAGAWA, M. ABC: Custeio Baseado em Atividades. 2. ed. São Paulo: Atlas, 2008.

NEGRINI, D.; KETTLE, A.; SHEPPARD, L. MILLS, G. H.; EDBROOKE, D. L. The Cost of a hospital ward in Europe: Is there a methodology available to accurately measure the costs? Journal of Health Organization and Management, v. 18, n. 3, p. 195-206, 2004.

OLIVEIRA, C. O Hospital do Futuro no Brasil. 2005. Disponível em: 〈http://www.ciahospitalar.com.br>. Acesso em: 17 jun. 2010.

RAIMUNDINI, S. L.; SOUZA, A. A.; BOTELHO, E. M.; STRUETT, M. A. M.; REIS, L. G. Análise da Aplicabilidade do sistema ABC em Hospitais e Congêneres. Contabilidade Vista \& Revista Belo Horizonte, v. 16, n. 2, p. 29-42, ago, 2005.

RAMOS, A. W.; MIYAKE, D. I. Desenvolvendo Indicadores de Produtividade e Qualidade em Hospitais: Uma Proposta de Método. Produto \& Produção, v. 11, n. 2, p. 67 - 84, jun. 2010 .

SANTOS, F. P. A Regulação Pública da Saúde no Brasil: o Caso da Saúde Suplementar. Tese (Doutorado em Medicina) - Pós-Graduação da Faculdade de Ciências Médicas da Universidade Estadual de Campinas - Saúde Coletiva. Campinas, 2006.

SHANDER, A.; HOFMANN, A.; OZAWA, S.; THEUSINGER, O. M.; GOMBOTZ, H.; SPAHN, D. R. Activity-based costs of blood transfusions in surgical patients at four hospitals. Transfusion, v. 50, p. 753-765, Apr, 2010.

SOUZA, A. A.; RAIMUNDINIDI, S. L.; KUWABARA, C. C. T. Análise do Sistema de Gestão de Custos de um Hospital Público. Rev. Faculdade São Camilo, Belo Horizonte, Minas Gerais, v. 2, n. 2, out. 2008.

St HILAIRE, C.; CRÉPEAU, P. K. Hospital and unit cost allocation methods. Health Care Management Forum, Vol. 13, No. 2, pp. 12-32, 2000.

STRUETT, M. A. Aplicação do Custeio Baseado em Atividades: estudo de caso em um laboratório de análises clínicas. FCV Empresarial, v. 1, p. 27-52, 2007.

TOYABEA， S.; CAOA,P.; KURASHIMAA， S.; NAKAYAMAB， Y.; ISHIIB， Y.; HOSOYAMAB, N.; AKAZAW, K. Actual and estimated costs of disposable materials used during surgical procedures. Health Policy, v. 73, p. 52-57, 2005.

TURNEY, P. B.; COMMON, C. The ABC performance break throught. Hillsboro: Cost Tecnology, 1991. 
VARGAS. O. C. O Custeio Baseado em Atividades Aplicado em Serviços Hospitalares.

Dissertação (Mestrado em Engenharia de Produção) - Programa de Pós-Graduação em Engenharia de Produção da Universidade Federal de Santa Catariana, Florianópolis, 2002.

WATERS, H. R.; HUSSEY, P. Pricing health services for purchasers - a review of methods and experience. Health Policy, v. 70, p. 175-184, 2004.

ZIMMERMAN, J. L. Accounting for decision making and control. 2 ed. Boston: Irwin Mc Graw Hill, 1997. 